\title{
Immediate Outcome of Percutaneous Balloon Mitral Valvotomy in Shahid Gangalal National Heart Centre, Bansbari, Kathmandu, Nepal
}

Nagma Shrestha ${ }^{1}$, Yadav Kumar Dev Bhatta ${ }^{1}$, Arun Maskey ${ }^{1}$, Rabi Malla ${ }^{1}$, Rajib Rajbhandari ${ }^{1}$, Subodh Kansakar $^{1}$, Ranjit Sharma ${ }^{1}$, Dharmanath Yadav ${ }^{1}$, Chandra Mani Adhikari ${ }^{1}$, Dipanker Prajapati ${ }^{1}$, Sujatha Kesavan $^{2}$, Sushan Shrestha ${ }^{3}$

${ }^{1}$ Department of Cardiology, Shahid Gangalal National Heart Centre, Bansbari, Kathmandu, Nepal

2 Department of Cardiology, Oxford Heart Centre, John Radcliffe Hospital, Oxford, United Kingdom

${ }^{3}$ Patan Academy of Health sciences, Patan, Kathmandu, Nepal

\section{Citation}

Nagma Shrestha, Yadav Kumar Dev Bhatta, Arun Maskey, et al. Immediate Outcome of Percutaneous Balloon Mitral Valvotomy in Shahid Gangalal National Heart Centre, Bansbari, Kathmandu, Nepal. Nepalese Heart Journal 2015; 12 (1): 11-14

\section{Key words}

Mitral stenosis, Percutaneous balloon mitral valvotomy, Rheumatic Heart Disease.

\section{INTRODUCTION}

The decrease of the incidence of Rheumatic heart disease (RHD) in developed countries had already begun in 1910, and it is now below 1.0 per $100000 .{ }^{1}$ However, RHD is still endemic in developing countries. Annually we have around $10 \%$ to $15 \%$ of patients admitted due to RHD in our hospital. ${ }^{2}$ Approximately

\begin{abstract}
Background and Aim: Percutaneous balloon mitral valvotomy is well established as safe and effective procedure for patients with mitral stenosis due to Rheumatic Heart Disease. There are some retrospective studies on safety and efficacy of it in different subgroups of patients from our centre. Our study aims to assess the safety, efficacy and outcome of it in Shahid Gangalal National Heart Centre, Kathmandu, Nepal.
\end{abstract}

Methods: A Single centre, prospective study was conducted from July 1st 2013 to June 31st 2014 in our centre. All the patients who underwent percutaneous balloon mitral valvotomy for moderate to severe mitral stenosis during the study period were included. Safety and efficacy of the procedure was analyzed.

Results: There were 262 patients enrolled in the study among which 194 (74\%) were females. Mean age of patients was $33.2 \pm 12.5$ years. Seventy patients $(26.7 \%)$ were in atrial fibrillation, six (2\%) were pregnant, three (1\%) had history of stroke, twelve (4.6\%) underwent previous surgical or balloon commissurotomy. The mean left atrial pressure reduced from $26.8 \pm 8.9 \mathrm{mmHg}$ to $15.6 \pm$ $7.2 \mathrm{mmHg}(p<0.05)$. The mean mitral valve area increased from $0.9 \pm 0.17 \mathrm{~cm} 2$ to $1.6 \pm 0.28 \mathrm{~cm} 2$ $(p<0.05)$. Forty nine patients $(18.7 \%)$ developed moderate to severe mitral regurgitation. There was no mortality related to the procedure. The procedural success was achieved in $84 \%$ patients.

Conclusion: Our study suggests that percutaneous balloon mitral valvotomy is a safe and effective procedure for symptomatic mitral stenosis patients.

Corresponding Author

Nagma Shrestha

Department of Cardiology,

Shahid Gangalal National Heart Centre,

Kathmandu, Nepal

E-mail:nagmashrestha@gmail.com

| NHJ | Jan 2015 | Volume 12 | No.1 
$25 \%$ of all patients with RHD have pure mitral stenosis (MS), and an additional 40\% have combined MS and mitral regurgitation (MR). ${ }^{3-5}$

Based upon the nature and severity of MS, patients can be managed with medical management, Percutaneous balloon mitral valvotomy (PBMV) or surgery. PBMV has emerged as an alternative to surgical mitral commissurotomy for the treatment of symptomatic patients with MS. After its introduction in 1984 by Inoue et $\mathrm{al}^{6}{ }^{6}$, the technique evolved rapidly.

PBMV is recommended as a Class I indication for symptomatic patients (NYHA functional class II, III or IV), with moderate to severe MS and valve morphology favourable for PBMV in the absence of left atrial (LA) thrombus or moderate to severe MR. ${ }^{7}$ There are some retrospective studies conducted on safety and efficacy of the procedure in different subgroups of patients in our centre. ${ }^{8,9}$ Looking at the burden of disease and the result of retrospective studies, we aim to carry out a prospective study to assess the safety, efficacy and outcome of PBMV.

\section{METHODS}

It is a prospective, single centre study conducted at Shahid Gangalal National Heart Centre, Kathmandu, Nepal from July 1st 2013 to June 31st 2014. Ethical approval was taken from the Heart centre ethical committee. Informed consent was taken from the patient and patient's relative. Two hundred and sixty two consecutive patients who underwent PBMV for moderate to severe MS during the study period were included in this study. Those patients who underwent rescue PBMV were excluded from the study. Performa was designed to collect patient information which included; age, gender, medication, pulmonary artery systolic pressure, LA size, rhythm, mitral valve area (MVA) and mean LA pressure before and after PBMV.

All patients with symptomatic moderate and severe MS with favorable mitral valvemorphology were included. Patients with more than moderate MR, having other significant valve lesions requiring surgical treatment, or evidence of LA and left atrial appendage (LAA) thrombus were excluded. All the emergency cases were excluded from the study. In patient taking anticoagulant PT/INR was checked on the day of PBMV. Patients underwent PBMV only when PT/INR was below 1.5 to decrease the risk of bleeding.

PBMV was done with all aseptic condition through right femoral venous approach under local anaesthesia. The balloon catheter size was selected according to the patient's height using simple equation:(height $[\mathrm{cm}] / 10+10)$. Transseptal puncture was done using a Brockenbrough needle inserted via the right femoral vein. The LA mean pressures were recorded before and immediately after the procedure. ${ }^{2} \mathrm{D}$ echo, colour flow mapping and MVA calculation using planimetry was done before PBMV to evaluate MVA and MR. A trans- esophageal echocardiography (TEE) was done one day before the PBMV to rule out the presence of LA and LAA clot. Before discharge (on the next day of procedure) echocardiography was done to evaluate the MVA and MR.

Successful PBMV was defined as mean LA pressure decrease by $>50 \%$ as compared to the baseline, MVA increase by $>50 \%$ as compared to the baseline and final absolute mitral valve area of $>1.5 \mathrm{~cm} 2$ in the absence of more than moderate MR. Complications like cardiac tamponade, MR, CVA and acute pulmonary oedema were recorded.

\section{RESULTS}

Among the 262 patients included in the study 194 (74\%) were female. Their age range was from 10 years to 76 years and mean age was $33.2 \pm 12.5$ years. Atrial fibrillation was present in $70(26.7 \%)$ patients; $6(2 \%)$ patients were pregnant; $3(1 \%)$ patients had stroke, $12(4.6 \%)$ patients underwent previous surgical or balloon commissurotomy.

Table 1: Demographics.

\begin{tabular}{|l|r|r|}
\hline Male & 69 & $26 \%$ \\
\hline Female & 193 & $74 \%$ \\
\hline Atrial Fibrillation & 70 & $26.7 \%$ \\
\hline MR present & 168 & $64.1 \%$ \\
\hline No MR & 94 & $35.9 \%$ \\
\hline
\end{tabular}


Table 2: The MVA and mean LA pressure Pre and Post PBMV

\begin{tabular}{|l|l|l|l|}
\hline Parameters & Pre-PBMV & Post-PBMV & P value \\
\hline MVA $(\mathrm{cm} 2)$ & $0.9 \pm 0.17$ & $1.6 \pm 0.28$ & $<0.05$ \\
\hline $\begin{array}{l}\text { Mean LA } \\
\text { pressure } \\
\text { (mmHg) }\end{array}$ & $26.8 \pm 8.9$ & $15.6 \pm 7.2$ & $<0.05$ \\
\hline
\end{tabular}

LAsize ranged from $3.3 \mathrm{~cm}$ to $7.9 \mathrm{~cm}$ with the mean of $4.97 \pm 0.76 \mathrm{~cm}$. MR was present in $168(64.1$ $\%)$ and the rest $94(35.9 \%)$ did not have any MR.

The procedural success was achieved in $84 \%$ patients. The mean LA pressure significantly decreased from $26.8 \pm 8.9 \mathrm{mmHg}$ before the procedure to $15.6 \pm 7.2 \mathrm{mmHg}(\mathrm{p}<0.05)$. The mean MVA significantly increased from $0.9 \pm 0.17 \mathrm{~cm} 2$ to $1.6 \pm 0.28 \mathrm{~cm} 2(\mathrm{p}<0.05)$. Moderate to severe MR was seen in 49(18.7\%) patients after PBMV but none of them required emergency mitral valve replacement. There was no mortality related to the procedure.

\section{DISCUSSIONS}

MS is sequel of RHD which occurs from leaflet thickening, commissural fusion, and chordal shortening and fusion. Closed mitral commissurotomy was first described by Harken and Bailey in the late 1940s. ${ }^{10}$ Subsequently, after the development of cardiopulmonary bypass, the open surgical commissurotomy replaced the closed technique in most countries in the late 1960s and early 1970s. In 1982, Kanji Inoue, a Japanese cardiac surgeon, first developed the idea that a degenerated MV could be inflated using a balloon made of strong yet pliant natural rubber. ${ }^{11}$ As demonstrated in pathologic and echocardiographic studies, the mechanism by which PBMV relieves MS is the same with that of surgical commissurotomy, that being the separation of the mitral leaflets along the fused commissures. After a decade of practice, the results and complications of PBMV compare favorably to those of the surgical commissurotomy. So, PBMV is now a well established treatment modality for moderate to severe MS.

There have been only few studies conducted on efficacy of PBMV in pregnancy, elderly and children. In a study conducted by Shrestha et al. $^{8}$ procedural success rate of PBMV in patients below 15 years of age was 94\%, similarly a study conducted in elderly by Adhikari et al. ${ }^{9}$ showed success rate of $83.6 \%$. However, all of these studies were retrospective.

Among 262 patients we analyzed MS was predominantly seen in female. Our procedural success rate was $84 \%$ which is comparable to previous studies by Nobuyoshi et al. (92\%) in Japan, ${ }^{12}$ Alkhalifa et al. (94.5\%) in Sudan, ${ }^{13}$ Arora et al. (99.8\%) in New Delhi, India. ${ }^{14}$ MR severity may increase in $25-83 \%$ of cases $12,14,15$ and 49 patients (18.7\%) in our study developed moderate to severe MR. There was no mortality related to the procedure.

Limitation of our study includes a single center, non randomized study with no long term follow up to evaluate long term outcome.

\section{CONCLUSION}

The results of this study show that PBMV is a safe procedure with good success rate for symptomatic MS. 


\section{REFERENCES}

1. Masakiyo Nobuyoshi, Takeshi Arita, Shin-ichi Shirai, et al. Percutaneous Balloon Mitral Valvuloplasty: A Review. Circulation. 2009;119:211-219.

2. Shahid Gangalal National Heart Centre, Annual Report: Medical Ward. Year 2011-2013.

3. Dare A. Evaluation of surgically excised mitral valves: Revised recommendations, based on changing operative procedures in the 1990s. Hum Pathol 1993; 24:1286.

4. Waller B, Howard J, Fess S. Pathology of mitral stenosis and pure mitral regurgitation-part I. Clin Cardiol 1994; 17:330.

5. Schoen EJ, St John Sutton M. Contemporary pathologic considerations in valvular heart disease. In Virmani R, Atkinson JB, Feuglio JJ. Cardiovascular pathology. Philadelhia, WB saunders Co, 1991, p334.

6. Inoue K, Owaki T, Nakamura, et al: Clinical applications of transvenous mitral commissurotomy by a new balloon catheter. J Thorac Cardiovasc Surg 1984; 87:394-402.

7. Robert OB, Blasé AC, Kanu C, et al. -2008 focused update incorporated into the ACC/AHA 2006 guidelines for the management of patients with valvular heart disease: A report of the American college of cardiology/ American heart association task force on practice guidelines (writing committee to revise the 1998 guidelines for the management of patients with valvular heart disease. J Am. Coll. Cardiol. 2008; 52;1-142.

8. Shrestha M, Adhikari CM, Shakya U, et al. Percutaneous Transluminal Mitral Commissurotomy in Nepalese children with Rheumatic Mitral Stenosis. Nepalese Heart Journal 2013;10(1):23-26.

9. Chandra Mani Adhikari, Rabi Malla, Rajib Rajbhandari, et al. Percutaneous Transvenous Mitral Commissurotomy in Elderly Mitral Stenosis Patients. A Retrospective Study at Shahid Gangalal National Heart Centre, Bansbari, Kathmandu, Nepal. MAEDICA - a Journal of Clinical Medicine 2013; 8(4): 333-337.

10. Harken DE, Dexter L, Ellis LB, Farrand RE, Dickson JF III. The surgery of mitral stenosis: III: finger-fracture valvuloplasty. Ann Surg. 1951;134:722-742.

11. Inoue K, Owaki T, Nakamura T, Kitamura F, Miyamoto N. Clinical application of transvenous mitral commissurotomy by a new balloon catheter. J Thorac Cardiovasc Surg 1984;87:394402.

12. M Nobuyoshi, $\mathrm{N}$ Hamasaki, $\mathrm{T}$ Kimura, et al. Indications, complications and short-term clinical outcome of percutaneous transvenous mitral commissurotomy. Circulation 1989;80: 782-792.

13. M S Alkhalifa, Huda H M Elhassan, FASuliman, et al. Percutaneous Transmitral Balloon Commissurotomy [PTMC] Procedural success and immediate results at Ahmed Gasim Cardiac Center. Sudan JMS 2006;1(2):115-119.

14. Arora R, Kalra GS, Singh S, et al. Percutaneous transvenous mitral commissurotomy: immediate and long-term follow-up results. Catheter cardiovasc interv. 2002; 55(4):450- 456.

15. Essop MR, Wisenbaugh T, Skoularigis J, et al. - Mitral regurgitation following mitral balloon valvotomy. Differing mechanisms for severe versus mild-to-moderate lesions. Circulation 1991; 84:1669-1679. 